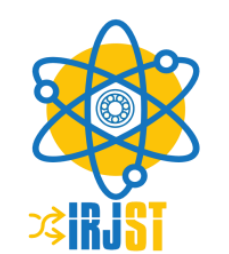

Available online at https://www.irjst.com/

International Research Journal of Science and Technology

ISSN: $2707-3955$

DOI: https://doi.org/10.46378/irjst.2021.020301

\title{
A Checklist of Arthropods Recorded on Exposed Pig Carrion in Neke, Enugu State, Nigeria.
}

\section{Odo.P.E*, Iloba.B. N}

Department of Animal and Environmental Biology, Faculty of Life Sciences, University of Benin, Benin City, Edo State, Nigeria.

\begin{tabular}{lll}
\multicolumn{2}{l}{ Paper Status } \\
Received : & Arp 2021 \\
Accepted : & Jun 2021 \\
Published : & Jun 2021
\end{tabular}

Key Words

Carrions

Entomotoxicology

Enugu State

Forensic Entomology

Forensic Entomology

Neke

\begin{abstract}
A comprehensive study of insects recovered on the decaying pig was carried out from 7th June to 7th September, 2018 to identify the arthropods connected with the pig carrions. The study revealed that Diptera, Coleoptera, Hymenoptera and Isoptera were the group of insects that were collected on the carrions. At the fresh stage, there were 78 insects and at the bloated stage there were 182 insects while at the active decay stage there were 262 and at the advanced decay stage there were 319 insects as the dry decay stage yielded only 119 insects. The Simpson index was high (0.95) in the active decay and advanced decay stages but was low (0.89) in the fresh and dry decay stages. The Dominance index was high $(0.11)$ in the fresh and dry decay stages of but was low (0.05) in the active and advanced decay stages and the Shannon-Weiner index $(\mathrm{H})$ was high (3.09) in the advanced decay stage but low (2.33) in the dry decay stage. The Evenness index (E) was high (0.95) in the fresh stage but low (0.86) in the dry decay stage. Richness index: Margalef (R) was high (4.03) in the advanced decay stag but was low (2.07) in the fresh stage as the Equitability index was high (0.98) in the fresh and bloated stages but low (0.94) in the dry decay stage. The score plot of the PCA shows a scatter plot of species distribution in carrion for components 1 and 2 . Component 1 accounted for $42.3 \%$ of the variation in the dataset while component 2 accounted for $24.6 \%$ making a total of $66.9 \%$.
\end{abstract}

Copyright (C) 2021: Odo.P.E, Iloba.B. N. This is an open-access distribution, and reproduction in any medium provided Access article distributed under the Creative Commons Attribution License the original work is properly cited License, which permits unrestricted use.

Citation: Odo.P.E, Iloba.B. N. "A Checklist of Arthropods Recorded on Exposed Pig Carrion in Neke, Enugu State, Nigeria”, 2 (3), 423-433, 2021.

\section{Introduction}

Medicolegal forensic entomology is one of the branches of the wide field of entomology that is always implicated in carrion ecological practice. Despite the fact that arguments concerned with the other branches of forensic entomology; urban and stored products steadily take place, medicolegal forensic entomology mainly is the area that is directly used by criminal investigators in the revelation of hidden issues about troublesome crimes.

\footnotetext{
* Corresponding Author: Odo.P.E

Department of Animal and Environmental Biology, Faculty of Life Sciences, University of Benin, Nigeria.

Email: odopatrickemeka@gmail.com
}

Arthropods evidences are very indispensable in the determination of proper and exact time that death took place known as post-mortem interval (PMI), the cause of death and place of death especially when the arthropod fact and concept is the cardinal variable in a criminal investigation [1].

There have been existing relationship between arthropod attraction and interaction with animal carrions with cordial usage of this fact in the determination of hidden truths about the death of animal including man worldwide. However, medicolegal forensic entomology is till now assumed to be understudied. Despite the fact that several authors globally have made efforts of documenting their finding on this new area, very few of this type of 
studies have been done in Nigeria. Researchers like [2, $3,4,5,6,7,8,9$ and 10] are among the few carrion ecologists that made efforts in the creation of databases of insects of forensic importance in Nigeria.

However, there is growing interest and awareness of the public and law enforcement agencies on the concept of forensic entomology and entomotoxicology in criminal investigation in Nigeria these days. Its practical usefulness in Nigeria legal system is still unknown and unpopular to compare to other areas of entomology such as medical and agricultural entomology.

Arthropods are ubiquitous, being found in almost all the environmental and habitat types, because of this fact, they are always the first organisms to be attracted to the death organisms and serve as indicators of dead incidence.

These organisms are always implicated colonizing animal cadavers as well as animal dung and rotten fruits. A forensic entomologist recognizes this fact and takes the opportunity in the determination of important issues surrounding unexplainable deaths by systematically collecting arthropods both adults and immature stages and process the facts arriving from their careful studies over death circumstances.

However these experts on carrion ecology must know what exactly they want in crime scene and must have a comprehensive understanding of insects' biology and anatomy especially with regards to the Coleoptera and Diptera. These will enhance careful search, recognition and assemblage of these arthropod specimens for evidence [11] well as proper identification of these entomofauna from Kingdom to species. This study is concerned with the creation of a comprehensive database of insects of forensic importance on pig carrions in Neke, Enugu State, Nigeria during the wet season.

\section{Material and Methods}

\subsection{Study Area}

The present research took place in Neke town of the eastern State of Enugu. Neke (Fig 1) is a pure Guinea Savannah vegetation type of woodland and tall grasses. It has tall and short grasses with palm trees and other economic trees. The dominant activity here is farming. This farmland lies between $06^{\circ} 45^{\prime} 30^{\prime \prime} \mathrm{N}$ and $07^{\circ} 43^{\prime} 09^{\prime \prime} \mathrm{E}$.

The temperature ranges between 34-39 0C and lies within the south eastern part of the country. It is made up of two seasons, the dry and the rainy seasons, the rainy season starts from April and ends in October while the dry season starts in November and ends in March with a cold Hammattan between December and February.

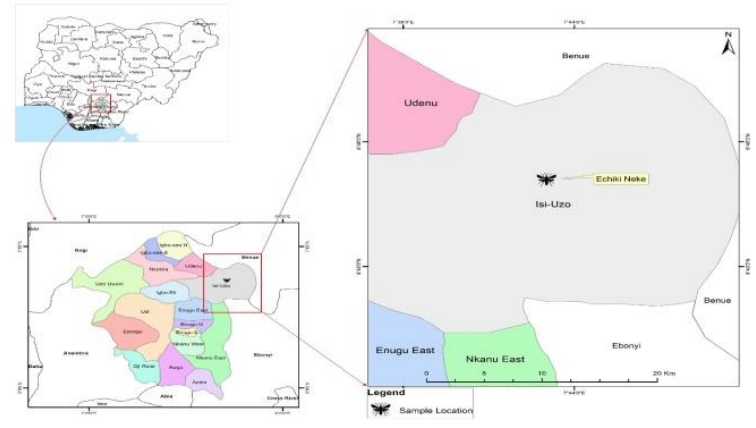

Figure 1. Map of the study area

\subsection{Experimental Animals}

In this study pigs was used to mimic human cadaver.

\subsection{Experimental Set-Up for the Succession Studies}

This study took place between 7th June and 7th September 2018. Three pigs were used in this study (three replicate), each pig was stabbed in the thorax, under the foreleg with a sharp knife to simulate a typical homicide wound, each killing was around 6.00 $\mathrm{pm}$ before the beginning of this research work and the day of their death was counted as day 0 on each trial. The carrions were placed into heavy trash bags and carried from the killing place to the respective studying sites.

The pig carrions were deposited on the ground, guarded against vertebrate scavengers with wire mesh that allows ingress of all the flies and other arthropods and protected the carrions against the other bigger animals. The wire meshes of $160 \mathrm{~mm} \times 100 \mathrm{~mm} \times 30 \mathrm{~mm}$ were used to form iron cages that were removed on each sampling occasions. There were an inter carcass distances of at least $40 \mathrm{~m}$ to minimize interruption of flies from adjacent carrions. There were an inter carcass distances of at least $40 \mathrm{~m}$ to minimize interruption of flies from adjacent carrions $[12,13]$.

\subsection{Insects Sampling Methods in the Succession Studies}

The samples for the entomofauna were collected two times per day at 10 and 14.00 GMT for the initial week, while once daily for the remaining weeks. Insects were collected manually by the application of hand nets and sweep nets for flying insects; these flying insects were collected by making fifteen swipes with the sweep net in each sampling occasion, while brushes were used to comb round the animal bodies to collect those insects that were found on the bodies and hand picking were also used manually.

Pitfall deceptions were also applied for crawling bugs as the soil just underneath the rotting carrions were continually perused to collect any stage of insect hiding around as the age of the pupae were difficult to estimate. Second instars maggots were assembled from 
the rotting carrions and the larvae from each carrion were grown in the translucent plastic dishes with depth of $15 \mathrm{~cm}$ and width diameter of $11.5 \mathrm{~cm}$ at $25^{\circ} \mathrm{C}$ each (with muslin cloth covering and rubber bands that permitted aeriation and hindered the seepage of the insects) containing saw-dust and part of the putrefying carrion-remains to feed the immature insects, the second instars larvae were reared till adult stage [13].

The adult beetles that emerged from the rearing containers simply collected with forceps straightaway the rearing cloth was removed and preserved in $80 \%$ ethanol respectively. These developed adult beetles and flies were sorted to their taxonomic groups for documentation [9, 14].

\subsection{Insects' Identification}

Existing keys of identification of insects were applied in the identification of the insects that were collected in this research work. Different Orders, family, species and Genus were identified using [15]. For Diptera: [16, 17, 18, 19, 20], Coleoptera: [21, 22, 23, 24]. For Hymenoptera: [25, 26, 27, and 28].

\subsection{Data analysis}

Microsoft excel and the statistical package for social sciences (SPSS) and graphs were used to establish the relation amongst the orders of insects and their numbers collected on the decaying carrion and the stages of decomposition and their respective period taken for each of the period of rottenness. Diversity indices (Dominance index, Simpson index, Shannon wiener index, Evenness index, Margalef index and Equitability index) were used to analyze the species diversity, abundance and distribution in the study area while PCA for the distribution of frequency of occurrence of species at the different stages of decomposition

\section{Results}

\subsection{The carrion decomposition pattern and entomofauna of the different stages of decomposition}

The first insects' species to visit the decaying pig carrion was $L$. sericata at about 4.20 minutes after exposure. The entire period of decay was 60 days, the initial stage was just 2 days (3\%) of the entire period of decomposition while the second (bloated) stage of putrefaction lasted for 2 days (3\%) of the entire time of decay and the active decay phase lasted for 4 days (7\%) and the advanced decay took for 6 days (14\%) but the dry decay of lasted for till 60 days $(73 \%)$ of the entire period respectively. However, 960 insects were collected, 78 at the fresh stage, 182 at the bloated stage, 262 at the active decay stage of decomposition, 319 and 119 at the advanced decay and dry decay stages of decomposition respectively ( Table 7 and Figure 2).

At the fresh stage of decomposition, the period started from day 0 and stopped on the day 2, took only 2 days of the decomposition while the number of insects collected were 78 (Table 7) but the predominant insects species at this stage was S. evanida and C. chloropyga while the first insects to visit the pig carrion immediately after exposure was L.sericata.

However, only 2 Orders of insects were recorded at this stage of decomposition, 4 families and 10 species respectively. The Orders were Diptera and Hymenoptera, while the Families were Calliphoridae, Sarcophgidae, Muscidae and Formicidae (Table 1).

At the bloated stage of decomposition, the first sign of bloating started on the day 3 and ended on the day 4, lasted for just 2 days and took only $3 \%$ of the entire period of decomposition (Table 7 and Figure 2). The predominant insect's species was the Crematogaster sp. There were 3 orders of insects at this stage of decomposition; Diptera, hymenoptera and Coleoptera while the 8 Families and 18 species were equally recorded on the decomposing pig carrions. The implicated insects Families were Drosophilidae, Calliphoridae, Muscidae, Sarcophgidae, Formicidae, Apidae, Cleridae and Staphylinidae (Table 2).

At the active decay stage of decomposition, the period started on the day 5 and stopped on the day 8 , took only 4 days out of the 60 days of decomposition (Table 6 , Figure 1) but the predominant insect species was Drosophilis sp. However, 3 insects Orders were recorded, the Diptera, Coleoptera and Hymenoptera while 13 families and 25 species were equally recorded on the decomposing pig carrions respectively. The Families recorded were Bombylidae, Calliphoridae, Drosophilidae, Muscidae, Sarcophagidae, Ulididae, Cleridae, Dermestidae, Histeridae, Silphidae, Cocchilinidae, Formicidae and Apidae (Table 3).

At the advanced decay phase, the period started on the day 9 and ended on the day 16 (8 days and 14\%) of the entire decomposition period was spent on this stage of decomposition (Table 6 and 1) and the numbers of insects encountered at this stage of decomposition were 319 , but 127 were Diptera, 45 were Hymenoptera and 147 were Coleoptera (Table 7 and Figure 2). there were only 3 insects Orders, 14 Families and 26 species respectively. The Orders of Diptera, Coleopteran and Hymenoptera while the Families of Calliphoridae, Drosophilidae, Muscidae, Sarcopohagidae, Ulididae, Carabeidae, Cleridae, Cocchilinidae, Silphidae, Dermestidae, Staphylinidae, Tenebrionidae, Apidae and Formicidae (Table 4). 
Table 1. Entomofauna of the fresh stage of decomposition of the pig

\begin{tabular}{lllll}
\hline Order & Family & Genus/species & $\begin{array}{l}\text { Life } \\
\text { stage }\end{array}$ & Number \\
\hline Diptera & Calliphoridae & Chrysomya. rufufacies & A & 4 \\
, &, & Luciia. sericata & A, I & 7 \\
, & Chrysomya sp & A & 6 \\
, &, & Chrysomya chloropyga & A, I & 12 \\
, &, & Chrysomya albiceps & A, I & 9 \\
, & Sarcophagidae & Sarcophaga exuberans & A, I & 7 \\
, & Muscidae & Musca domestica & A & 8 \\
, &, & Stomoxys evanida & A & 12 \\
, &, & Isomyia evanida & A & 8 \\
Hymenoptera & Formicidae & Crematogaster sericeus & A & 5 \\
\hline
\end{tabular}

Table 2 Entomofauna of the bloat stage of decomposition of the pig Carrion

\begin{tabular}{lllll}
\hline Order & Family & Genus/ species & Life stage & Number \\
\hline Diptera & Drosophilidae & Drosophilia sp. & A & 11 \\
, & Calliphoridae & L. sericata & A, I & 12 \\
, &, & Chrysomya sp. & A & 12 \\
, & Chrysomya albiceps & A, I & 10 \\
, & Chrysomya regalis & A, I & 13 \\
, &, & Chrysomya. rufifacies & A, I & 11 \\
, & Muscidae & Musca domestica & A, I & 12 \\
, &, & Stomoxys evanida & A & 9 \\
, &, & Isomyia evanida & A, I & 10 \\
, & Sarcophagidae & Sarcophaga exuberans & A, I & 12 \\
, &, & Sarcophaga inzi & A, I & 9 \\
Hymenoptera & Formicidae & Crematogaster sp. & A & 14 \\
, &, & Pheidole sp. & A & 10 \\
, & Apidae & Apis mellifera & A & 04 \\
, &, & Trigona carbonaria & A & 02 \\
Coleoptera & Cleridae & Necrobia ruficolis & A & 07 \\
, &, & Necrobia rufipes & A & 11 \\
, & Staphylinidae & Staphylinus violaceous & A & 06 \\
\hline
\end{tabular}


Table 3. Entomofauna of the Active Decay stage of decomposition of the pig Carrion

\begin{tabular}{|c|c|c|c|c|}
\hline Order & Family & Genus/ species & Life stage & Number \\
\hline Diptera & Bombyllidae & Petrorossia sp & $\mathrm{A}$ & 11 \\
\hline , & Calliphoridae & C. rufifacies & $\mathrm{A}, \mathrm{I}$ & 9 \\
\hline , & , & Chrysomya chloropyga & $\mathrm{A}, \mathrm{I}$ & 12 \\
\hline , & , & Chrysomya albiceps & $\mathrm{A}, \mathrm{I}$ & 6 \\
\hline , & $"$ & Chrysomya regalis & $\mathrm{A}, \mathrm{I}$ & 13 \\
\hline , & " & L. sericata & A & 8 \\
\hline , & Drosophilidae & Drosophilia sp. & A & 23 \\
\hline, & Muscidae & Musca domestica & $\mathrm{A}, \mathrm{I}$ & 18 \\
\hline , & , & Stomoxys evanida & $\mathrm{A}, \mathrm{I}$ & 12 \\
\hline ", & , & Isomya evanida & $\mathrm{A}, \mathrm{I}$ & 9 \\
\hline , & Sarcophagidae & Sarcophagi inzi & $\mathrm{A}, \mathrm{I}$ & 2 \\
\hline , & , & Sarcophagi exuberans & $\mathrm{A}, \mathrm{I}$ & 9 \\
\hline , & Ulidiidae & Physiophora sp & A & 7 \\
\hline Coleopteran & Cleridae & Necrobia ruficolis & A & 8 \\
\hline, & , & Necrobia rufipes & A & 12 \\
\hline ", & Dermestidae & Dermestid maculatus & A & 2 \\
\hline , & Histeridae & Hister monitor & A & 3 \\
\hline ", & Silphidae & Thanatophilus sinuatus & A & 07 \\
\hline, & Cocchilinidae & Harmonia axyridis & A & 12 \\
\hline Hymenoptera & Formicidae & Crematogaster $\mathrm{sp}$ & A & 16 \\
\hline, & , & Camponotus sericeus & A & 11 \\
\hline ", & , & Pheidole sp & A & 21 \\
\hline , & , & Oecophylla longinoda & A & 13 \\
\hline ", & Apidae & Apis mellifera & A & 06 \\
\hline , & , & Trigona carbonaria & A & 12 \\
\hline
\end{tabular}

Table 4. Entomofauna of the Advance Decay stage of decomposition of the pig carrion

\begin{tabular}{lllll}
\hline Order & Family & Genus/ specie & Life stage & Number \\
\hline Diptera & Calliphoridae & C. rufifacies & A, I & 6 \\
$"$ & $\#$ & Chrysomya sp & A, I & 12 \\
, & $"$ & Chrysomya albieps & A, I & 14 \\
$"$, & L.sericata & A & 09 \\
, &, & Chrysomya regalis & A, I & 08 \\
, & Drosophilidae & Drosophilia sp & A & 12 \\
$"$ & Muscidae & Musca domestica & A, I & 18 \\
, &, & Stomoxys evanida & A, I & 12 \\
\hline
\end{tabular}




\begin{tabular}{lllll}
\hline, &, & Isomyia evanida & A & 07 \\
, & Sarcophagidae & Sarcophagi inzi & A, I & 09 \\
, &, & Sarcophagi exuberans & A, I & 12 \\
, & Ulidiidae & Physiophora sp & A, I & 08 \\
Coleoptera & Carabeidae & Chlaenus dasaulti & A & 05 \\
, & Cleridae & Necrobia ruficolis & A & 12 \\
, &, & Necrobia rufipes & A & 19 \\
, & Coccinelidae & Harmonia axyridis & A & 12 \\
, & Silphidae & Thanatophilus sinuatus & A & 21 \\
, & Dermestidae & Dermestid maculatus & A, I & 17 \\
, & $\#$ & Dermestid ater & A, I & 12 \\
, & Staphylinidae & Philonthus sp & A & 16 \\
Hymenoptera & Tenebrionidae & Alphitobius sp & A & 7 \\
,$"$ & Formicidae & Trigona carbonaria & A & 05 \\
, &, & Camponotus sericeus & A & 12 \\
, &, & M. minimum & A & 19 \\
\hline
\end{tabular}

Table 5. Entomofauna of the Dry Decay stage of decomposition of the pig Carrions

\begin{tabular}{lllll}
\hline Order & Family & Genus/species & Life stage & Number \\
\hline Diptera & Calliphoridae & Chrysomya albiceps & A & 04 \\
, & Muscidae & Musca domestica & A & 09 \\
, & Sarcophagidae & Sarcophaga inzi & A & 03 \\
Coleoptera & Dermestidae & Dermestid maculatus & A, I & 22 \\
, &, & Dermestid ater & A, I & 07 \\
, & Cleridae & Necrobia rufipes & A & 08 \\
, &, & Necrobia ruficolis & A & 14 \\
Hymenoptera & Formicidae & Crematogaster sp & A & 11 \\
, &, & Formica pallide-fulva & A & 05 \\
, &, & Monomorium minimum & A & 19 \\
, &, & Oecophylla longinoda & A & 06 \\
, &, & Solenopsis molesta & A & 11 \\
\hline
\end{tabular}

Table 6. Period of Decomposition of the Pig Carrions

\begin{tabular}{lll}
\hline Stage of Decomposition & $\begin{array}{l}\text { Period of Decomposition } \\
\text { (days) }\end{array}$ & $\begin{array}{l}\text { Length of decomposition } \\
\text { (days) }\end{array}$ \\
\hline Fresh & $0-2$ & 02 \\
Bloated & $3-4$ & 02 \\
Active decay & $5-08$ & 04 \\
Advance decay & $09-16$ & 08 \\
Dry decay & $17-60$ & 43 \\
\hline
\end{tabular}


At the dry decay stage of decomposition, the period was the longest of all other stages of decomposition, it lasted for 43 day, from the day 17 to the day 60 taking $73 \%$ of the entire period of decomposition while the predominant insects species was D. maculates. There were 3 Orders, 5 Families and 12 species only. Diptera, Coleoptera and Hymenoptera while the Families were Calliphoridae, Sarcophagidae, Dermestidae, Cleridae and Formicidae. (Table 5)

\subsection{The Period of Decomposition of Pig Carrions}

The fresh stage of decomposition started from the day 0 and ended on the day 2, took only 2 days and $3 \%$ of the entire period of decomposition while the bloated stage started on the 3 and ended on the day 4, lasted for 2 days and took $3 \%$ also but the active decay stage of decomposition was from day 5 to day 8 took $7 \%$ and lasted 4 days out of the entire 60 days of the entire decomposition and the advanced decay stage of decomposition started on the day 9 and ended on the day and lasted till day 16, took 8 days and $14 \%$ out of the entire period of decomposition but the dry decay stage of decomposition started from day 17 and ended on day 60 taking 43 days and $73 \%$ of the entire period of decomposition (Table 6).

\subsection{Frequencies Insects Encountered at the Stages of Decomposition}

There were 960 insects recorded during wet season and station 3, at the fresh stage of decomposition, there were 78 insects, at the bloated stage of decomposition, there were 182 insects while at the active decay stage of decomposition, there were 262 and at the advanced decay stage of decomposition, there were 319 insects but at the dry decay stage there were only 119 insects respectively.

At the fresh stage of decomposition, 73 were Diptera while 5 were hymenoptera while there no Coleoptera and other Orders but at the boated stage of decomposition, there were 128 Diptera, 30 Hymenoptera and 24 Coleoptera, at the active decay stage of decomposition, there were 139 Diptera, 79 Hymenoptera and 44 Coleoptera and at the advanced decay stage of decomposition, the Diptera was 127. Hymenoptera was 45 while 147 were Coleoptera but at the dry decay stage of decomposition, Diptera was only 16, Hymenoptera was 52 while Coleoptera was 51 respectively.

However, Diptera was 483 in all the stages of decomposition, 73 of them were collected at the fr4esh stage of decomposition, 128 at the bloated stage of decomposition while at the active decay stage of decomposition, Diptera was 139 but reduced to 127 at the advanced decay stage and 16 at the dry decay stage of decomposition. There were 211 Hymenoptera, at the fresh stage of decomposition, there were only 5 but increased to 30 at the bloated stage of decomposition and at the active decay stage of decomposition, the Hymenoptera was 79 but reduced to 45 at the advanced decay stage while 51 was recorded at the dry decay stage of decomposition respectively.

On the Order Coleoptera, it was totally 266, there was none at the fresh stage of decomposition but at the bloated stage of decomposition, 24 was recorded and 44 at the active decay stage but at the advanced decay stage of decomposition, 147 was recorded and at the dry decay stage of decomposition, the frequency was 51 respectively (Table 7 and Figure 2).

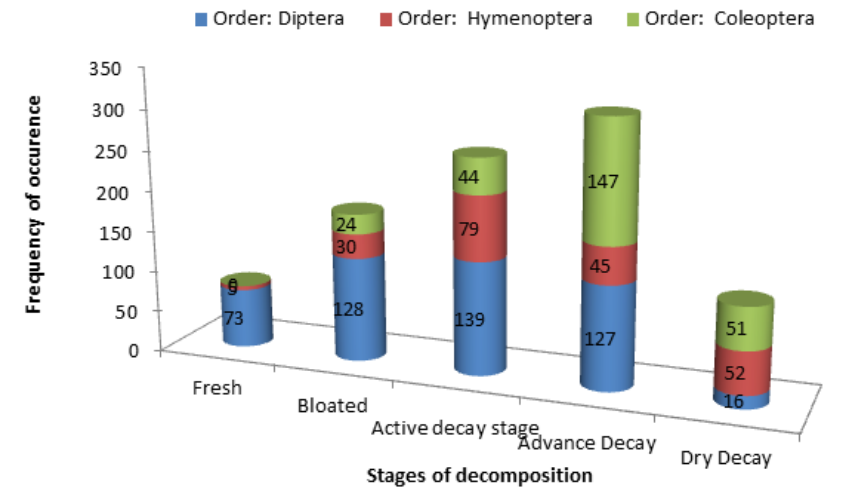

Figure 2. Number of Insects encountered at each stage of decomposition

3.4 Spatial species diversity during the wet season. Diversity index for the insect species in the decomposing pig carrion at the different stages of decomposition.

The Simpson index was high (0.95) in the active decay and advanced decay phases of but was low (0.89) in the fresh and dry decay phases. The Dominance index was high (0.11) in the fresh and dry decay phases of decomposition but was low (0.05) in the active and advanced decay phases of decomposition and the Shannon-Weiner index $(\mathrm{H})$ was high (3.09) in the advanced decay phase of decomposition but low (2.33) in the dry decay phase of decay (Table 8). The Evenness index (E) was high (0.95) in the fresh stage but low (0.86) in the dry decay phase respectively.

Richness index for the insect species in the decomposing pigs' carrion at the different stages of decomposition.

Richness index: Margalef (R) was high (4.03) in the advanced decay phase of decay but was low (2.07) in the fresh phase of decay respectively.

Equitability index for the insect species in the decomposing pig carrion at the different phases of decay .The Equitability index was high (0.98) in the fresh and bloated phase of putrefaction but low (0.94) in the dry decay phase of decay respectively. (Table 8) 
Table 8. Diversity for insect species at different stages

\begin{tabular}{llllll}
\hline Parameters & Stages & & & \\
\hline & Fresh & Bloated & Active decay & Advanced decay & Dry decay \\
\hline Number of samples & 10 & 18 & 23 & 24 & 12 \\
Individuals & 78 & 174 & 248 & 302 & 119 \\
Dominance & 0.11 & 0.06 & 0.05 & 0.05 & 0.11 \\
Simpson & 0.89 & 0.94 & 0.95 & 0.95 & 0.89 \\
Shannon H & 2.25 & 2.83 & 3.02 & 3.09 & 2.33 \\
Evenness Index & 0.95 & 0.94 & 0.89 & 0.91 & 0.86 \\
Margalef & 2.07 & 3.30 & 3.99 & 4.03 & 2.30 \\
Equitability & 0.98 & 0.98 & 0.96 & 0.97 & 0.94 \\
\hline
\end{tabular}
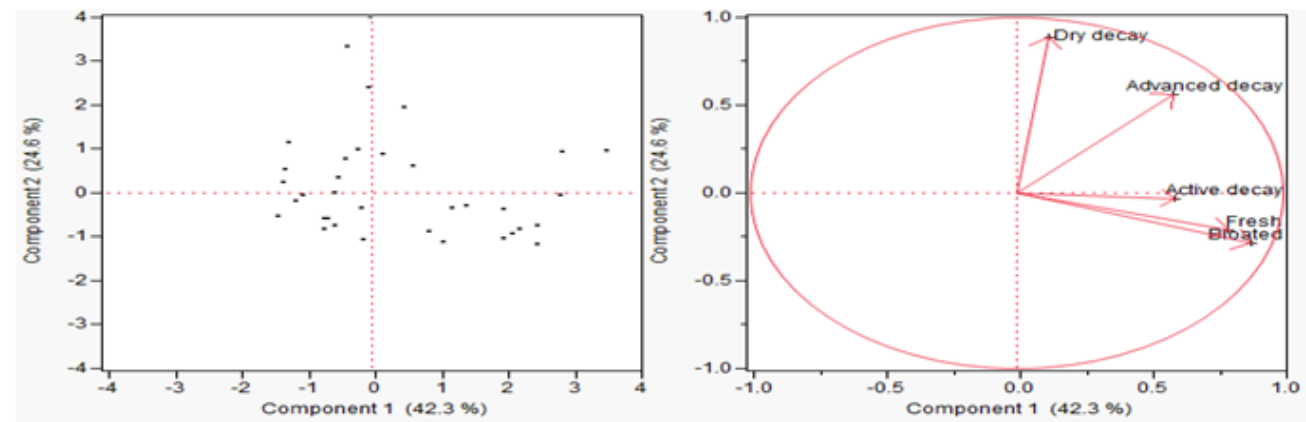

Figure 2. The PCA for the distribution of frequency of occurrence of species at the different stages of decomposition.

\subsection{The distribution of frequency of occurrence of species at the different stages (phases) of decomposition}

The score plan of the PCA demonstrated a scatter scheme of species spreading in carrion for constituents 1 as well as 2. Constituent (component) 1 accounted for $42.3 \%$ of the dissimilarity in the dataset while constituent (component) 2 accounted for $24.6 \%$ creating a total of $66.9 \%$. The loading plan indicates that fresh and bloated phases are crowded together and absolutely interconnected with the $1^{\text {st }}$ constituent (component) and negatively interconnected with the second constituent. The active decay phase is absolutely interconnected with constituent (component) 1 and deleteriously interconnected with constituent 2. However advanced decay and dry decay phases are absolutely interconnected with constituents (component) 1 and 2 respectively (Figure 3 ).

\section{Discussion}

This study makes available the basic database information of forensic importance insects in Neke, Enugu State, Nigeria on the pig carrions. It revealed that Diptera, Coleoptera, Hymenoptera and Isoptera are the group of insects that invaded feed and breed their offspring on the carrions. This research is very essential because there is no existing information of insects of forensic importance in Neke and other neighboring communities at this material time where information of insects that invade dead bodies are helpful and acceptable in the determination of the cause of death, time of death and place of death $[1,4$, $7,29,30]$

Insects are the arthropod group collected on decaying pig carrions in this study, the dominant insects' species recorded on the pig carrions were Diptera followed by Coleoptera and are also of forensic importance due to the fact that they visited the carrions to lay their eggs as well as feeding on both the carrions and other insect species and could be used in the determination of how long a carrion has been before recovering it. The essence of documenting the insects of forensic importance on animal model used to mimic human carrion is to compare the documented data with that of real human in the practical investigation that will be concerned with an unexplainable human death such as murder, assassination, among others.

In a real case, whenever the dominant groups of insects collected and documented on the pig carrions at a particular stage of decomposition is also recorded on human carrion, it could be deduced that the human carrion are also in that stage of decomposition at which that group were recorded on the pig carrions, however 
care must be taken in this type of decision as regard must be giving to the prevailing climatic condition, the presence of toxins, poisons, drugs among other substances that could alter the actual post-mortem interval of the carrion by either speeding up or slowing down the rate of decomposition and cause errors in the estimation of the time and cause of death [7,31].

A good number of insects' species recorded during this study have been also recorded in other carrion ecological studies both locally and internationally except few species. In the other studies carried out on insects of forensic importance on decaying carrions in the Southern Nigeria, most of these insects have been implicated except species like $T$. carbonaria, $T$. sinuatus, H. axyridis, C. dasaulti and Alphitobus sp [2, $3,4,9,12,13,14,31,32,33,34,35,35,37]$.

\section{Conclusion}

Based on the finding of this study, the insects' orders of Isoptera, Diptera, Hymeoptera and Coleoptera were the insects orders recovered from the decaying pig cadavers in Neke, Enugu State, Nigeria. The effects of the season and climatic condition were parameters that facilitated the presence and absence of the insect's species as many insects recovered in this study were not collected during the dry season. Diptera were the insects order with highest frequency on the carrion. For the fact that insects' life cycle can differ from one location to other and from a season to the other. This therefore research work should continue both in season and with different animal model to make sure that carrion ecology is utilized in the determination of hidden truth during criminal investigation related to unexplainable death in Neke and other neighboring communities.

\section{Acknowledgment}

The authors wish to acknowledge the traditional head of Echiki Neke, Isi uzo Local Government Area, Enugu State, Nigeria for enabling us to use their facility in the course of this study.

\section{Conflict of Interest}

There was no conflict of interest between the authors

\section{References}

[1]. CByrd, J. H. and Castner, J. L. (2001). Forensic Entomology, The Utility of Arthropods in Legal Investigations. CRC Press, Boca Raton, Fl.

[2]. Ekanem, M.S. and Dike, M. C. (2007). Arthropod succession on pig carcasses in South EasternNigeria. Pap Avulsos Zool (Sao Paulo); vol. 50(35):561-570

[3]. Okiwelu, S.N., Ikpamini, T. and Umezor. O.C. (2008). Arthropods associated with Mammalian carcasses in
Rivers State, Nigeria. African Journal of BiomedicalResearch, vol. 11: 339 - 342

[4]. Abajue, M.C., Ewuim, S.C. and Akunne. C. E. (2014). Preliminary checklist of fliesassociated with pig carrions decomposing in Okija, Anambra State, Nigeria. Annual Research international vol.11 (1): 1899 $-1904$

[5]. Ewuim, S. C. and Abajue, M.C. (2016). Forensic Entomology in Nigeria: The journey sofar.OpenScience Journal of Bioscience and Bioengineering 3(1):1-4

[6]. Ekrakene, T., Odo, P.E and Iloba. B.N. (2016)Effects of Tramadol Hydrochloride (an opioid) Injection on the Developmental Rate, Larval Weights and Body Lengths of Lucilia sericata (Meigen) (Diptera: Callophoridae) Reared on Rabbit (Orctylagus cunicunus) Carrions NISEB Journal vol. 16 (4): 148 - 153

[7]. Ekrakene, T. and Iloba, B.N. (2017). Effects of Killing on Decomposition of Pig (S.scrofa)Carrions in Benin City, Nigeria. Nigeria Journal of Entomology. $36: 1-6$.

[8]. Tekena, O. (2019). Insects of succession on Decomposing Guinea pig carrion at theCollege of Education, Warri, Delta State, Nigeria. A B.Sc (Ed). Project submittedto the Delta State University, Abraka.

[9]. Odo, P.E. and Iloba. B. N. 2020a). A Wet Season Study of Insects' Community and putrefying mannerof

Rabbit (Oryctolagus cuniculus) Carcasses at the College of Education, Warri,Delta State, Nigeria. J. Mat., and Environ. Sci., 2020, Volume 11, Issue 6, Page 885-895

[10]. Odo. P.E. and Iloba, B.N (2020b).Insects' Succession on the Decomposing Pig Carrion during the Wet Season at the College Of Education, Delta State, Nigeria. Samuel Adegboyega University Journal of Science and Technology (SAU SciTech. J) vol. 5(1)

[11]. Byrd, J. H. and Castner, J. L. (2010) Forensic Entomology, The Utility of Arthropods in Legal Investigations. CRC Press, Boca Raton, 23-681

[12]. Ekrakene, T. and Iloba, B.N. (2011).One death, Many Insects' generation. Journal of Entomology vol. 8 (1):27-39 
[13]. Ekrakene, T. and Odo. P.E. (2017). Comparative developmental effects of tramadol hydrochloride and Cypermethrine on Chrysomya albiceps (Dipera: Calliphoridae) reared on rabbit carrion. Science world Journal vol. 12 (1) 28-32. ISSN 1597-6343

[14]. Abajue, M.C., Ewuim, S.C. and Akunne. C. E. (2017). Insect's Larvae recovered from Decomposing Pig Carrions in Okija, Anambra State, Nigeria. Animal Research International vol. 14(2): $2764-2768$

[15]. Arnett Jr, R. H. and Jacques. R. L. (1981).Simon and Schuster's Guide to Insects. Simon and Schuster publishers, Newyork

[16]. Shaumar, N. and Mohammad. S (1983). Keys for identification of species of Family (Sarcophagidae: Diptera) in Egypt. J. Bull Soc Entomol .Egypt.

[17]. Shaumar, N.F., Mohammad, S.K.and Mohammad S.A. (1998). Keys for identification of species of family Calliphoridae (Ditpera) in Egypt. J. Egypt Soc Parasitol, vol.19 (2):669 681

[18]. Oldroyd. H. (1964). The Natural History of Flies. London: Weidenfeld and Entomologyvol.37:253 - 272

[19]. Zumpt. F. (1965). Myiasis in Man and Animals in the Old World, Butterworths, London

[20]. Denno, R.F. and Cothran. W.R. (1975).Niche Relationships of a Guild of Necrophagous Flies. Ann.Entomol. Soc. Am. Vol. 68: 741-754

[21]. Shaumar, N.F., Mohammad, S.K. and N.M. Salem. (1990).Taxonomic studies of Dermestidae (Coleoptera) in Egypt. J. Bull Soc. Entomol. Egypt. Vol. 69: 11-2

[22]. Dillon, E.S. and Dillon. L.S. (1961).A Manual of the Common Beetles of EasternAmerica. Evanston, Ill: Row, Peterson: p. 884

[23]. Lawrence, J. F. and Newton Jr. A. F. (1982). Evolution and classification of beetles. Annual Review of Ecology and Systematics vol. 13: 261-290

[24]. Almeida, M.L. and Mise. K.M. (2009).Diagnosis and keys to the main families andspecies of South America Coleoptera of Forensic important. Revista Brasileiva deEntomology vol. 53(2): 227-244

[25]. Brown Jr. W. L. (1955).Ant Taxonomy. In: Kessel E.W. (Ed.). A Century of
Progress inthe Natural Sciences, California Academy of Sciences, San Francisco, 1853-1953.

[26]. Radchenko. A.G. (1997).Review of Ants of the Genus Cataglyphis Foerster (Hymenoptera, Formicidae) of Asia. [In Russian.]. Entomol. Obozr. Vol. 76: 424-442

[27]. Bolton, S. (1994).Identification Guide to the Ant Genera of the World. HarvardUniversity Press, Cambridge, MA: p. 222

[28]. Bolton, G. Alpert, P. S. and. Ward, P. (2006) Bolton's Catalogue of Ants of the World. Harvard University Press, Cambridge, ISBN-10: 9780674021518, Massachusetts. 3658

[29]. German, G. P., Virgile, G., Razaki. O., Olivier, O., Esdra, O., Bruno, O. and M.Akogbeto (2017).First Evidence of Forensic Entomology revealed the presence of Arthropods on rabbit carrion in Cotonou, Benin (west Africa). International Journal ofEntomology Research $94-98$

[30]. Samford, M.R. (2017) Insects and associated arthropods during medicolegal death investigation in Harris country, Texas, USA. January 2013 - April 2016

[31]. Odo. P.E., Chidi, O. H. and Iloba, B.N. (2017) Insects Fauna Associated with decomposing Rabbit Carrion in Falcorp Mangrove Park, Ijala, Warri, Delta State,Nigeria. Book of Proceeding of the Faculty of Science international Conference of the Delta state University, Abraka

[32]. Tuduo, R., Odo. P.E., T. Ajemitolu, T. and Chidi, O. H. (2020). Arthropod Fauna Associated With Decomposing Guinea Pig (Cavia Porcellus) Carrion At The College Of Education Warri, Warri South Local Government Area, Delta State, Nigeria Nigerian Journal of Science and Environment, vol. 18 (1) 14 $-25$

[33]. Ekanem, M. S. (2008). Immature stages and developmental biology of two muscid flie (Cyclorrhapha: Diptera) which breed in carrion in Southern Nigeria. The Zoologist, vol. 6:16

[34]. Iloba, B.N. and Odigie, O.O. (2006).Arthropods succession on buried carrion of the Africa giant rat (Crycetomys gambianus). Africa Scentists vol.7 (2): 53-59 
[35]. Iloba, B.N. and Fawole, S.O (2006).Comparative insect fauna on exposed carrions across the vertebrate classes. International Journal of Biomedical and Health Sciences vol. 2(2): $51-66$.

[36]. Abajue, M.C., Ewuim, S.C. and Akunne, (2015). Insects Associated with decomposingpig carrions in Okija,Anambra State, Nigeria. Bioscientist vol. 1(1): 54- 59

[37]. Ekrakene, T., Odo, P.E. and Iloba, B.N. (2016). Effects of Tramadol Hydrochloride (anopioid) Injection on the Developmental Rate, Larval Weights and Body Lengths oftheLucilia sericata (Meigen) (Diptera: Callophoridae) Reared on Rabbit (Orctylagus cunicunus) Carrions. NISEB Journal Vol. 16, No. 4. 